\title{
Rehabilitation Counsellor's Role in Enhancing Work and Quality of Life for Cancer Survivors
}

\author{
Amani A Kettaneh*, Debra A Harley and Tala M Maya U \\ Department of Early Childhood, University of Kentucky, USA
}

*Corresponding author: Amani A Kettaneh, PhD, CRC, Department of Early Childhood, Special Education, and Rehabilitation Counselling, University of Kentucky, 212 D Taylor Education Building, Lexington, KY 40506, USA

Submission: 㯺 March 16, 2018; Published: 此 April 11, 2018

\begin{abstract}
The rehabilitation counsellor works with people with disabilities to assist them in ways to improve their quality of life and vocational outcomes. The types of disabilities among people are diverse, multifaceted, and vary in severity. One such disability group is individuals with cancer. Persons with cancer account for a minimal percentage of the total successfully closed vocational rehabilitation cases. Over the past few decades, the prognosis of many types of cancer has improved, with a resulting increase in the number of cancer survivors who have the ability to resume work after treatment and therapy. This article provides a comprehensive review of rehabilitation counsellors' involvement in enhancing the lives of individuals with cancer including the employment means, psychosocial impacts, and effective interventions to employ these goals.
\end{abstract}

Keywords: Cancer; Employment; Psychological impact; Social integration; Survivors; Vocational goals

\section{Rehabilitation Counsellors' Role in Enhancing Work and Quality of Life for Cancer Survivors}

Caner is a complex group of debilitating diseases, which result from uncontrolled growth of abnormal cells, and can originate in any organ system of the body [1]. Although cancer incidence rates are increasing, recent studies suggest that cancer patients are showing higher cure rates as well as improved overall survival rates for most cancer diagnoses [2,3]. These advances are explained by improved strategies in early detection as well as improved cancer therapies [4]. The number of long-term cancer survivors has also increased, but few studies have focused on vocational aspects and psychosocial issues of this subgroup. Some studies show that overall quality of life of long-term cancer survivors is quite high and comparable to that of the general population [5]. Nevertheless, a substantial percentage of former patient's exhibits reduced quality of life and may experience various complications and negative consequences of cancer [4]. In fact, because of the substantial negative consequences the Vocational Rehabilitation Act of 1973 designated cancer as a disease resulting in severe disability requiring priority services. Under the Americans with Disabilities Act (ADA), cancer is considered a disability when it limits one or more of a persons' major life activities.

Although many individuals with cancer continue to work during and after treatment, reduction of work hours or discontinuing work is common [6-9]. Increasingly, as treatments for cancer have changed, some forms of cancer are being seen as chronic diseases rather than as terminal. Nevertheless, cancer recovery is still associated with poorer overall quality of life and disabling longterm residual symptoms, such as fatigue, depression, pain, and functional limitations compared to the general population $[5,10]$.

Cancer patients have a higher risk of unemployment and are more vulnerable to emotional distress, which has negative social and economic impacts on them and on the society at large. After diagnosis, between twenty-six to fifty-three percent of cancer survivors quit working or lost their job over a period of seventytwo months. In addition, cancer patients had a decline in work ability, and temporary alterations in work hours, work schedules, and wages after diagnosis [11]. Research has shown that people with cancer often experience changes in workplace relationships or employment status, with negative financial and psychosocial consequences [12,13]. This article provides a comprehensive review of the impacts of cancer on employment, psychological factors and social interactions. It also discusses the rehabilitation counsellor role in counselling with and advocating for cancer survivors with the goal of enhancing their work opportunities and quality of life. In this article, cancer survivors are defined as those individuals in remission.

\section{Work and Employment for Cancer Survivors}

An important aspect of regaining a normal life after cancer is returning to work, which is often seen by cancer survivors as an 
important part of their recovery $[8,14]$. The loss of work of cancer survivors is associated with lower quality of life, lower self-esteem, and a decline in financial resources [15]. Unfortunately, not all cancer's survivors return to work. A recent meta-analysis indicated that the risk of unemployment is $37 \%$ higher for cancer survivors compared to healthy controls [16]. There is considerable work loss in the six months following diagnosis. For example, in a recent qualitative study among 504 cancer survivors Bradley et al. [17] found that approximately $30 \%$ of those employed prior to diagnosis were no longer working six months following the diagnosis. Among patients who remained employed, they worked fewer hours per week than they worked prior to cancer diagnosis about \%10 less.

Cancer diagnosis and treatment are associated with a high prevalence of job absenteeism. Job absenteeism is an important economic outcome because days missed from work are costly to both the employer and employee. Furthermore, the longer people are absent from their jobs, the lower the likelihood that they will ever return to work [18]. The employer and society at large are negatively affected due these influences on disability pensions and loss of productivity [19]. Typically, cancer survivors get little advice from their treating physicians about return-to-work issues, and they experience a lack of guidance from their general practitioners or occupational physicians as well [20]. There is limited information available to inform cancer survivors about the possible impact of cancer, its treatment and long-term side effects on work. There is also limited information on the work accommodations and adjustments that can be made available and how to access them [20]. It is not surprising that many people with cancer who remain at work throughout treatment experience difficulty managing their work due to coping with physical changes, emotional pressures and fatigue associated with cancer and its treatment [21]. With the increase in cancer survivorship, there is a need to address these work stresses and the quality of working life of cancer survivors. Rehabilitation and healthcare counsellors have a critical role in supporting this aspect of cancer survivorship. In order to encourage the provision of appropriate services to cancer's survivors, a comprehensive review of employment issues faced by cancer survivors will be discussed. Factors that may affect attaining/ maintaining employment include the meaning of employment for cancer survivors as well as the rehabilitation counsellor role in helping these individuals in achieving this vocational goal.

\section{Issues in Return to Work}

A number of studies suggest that the impact of cancer on work status may be transient rather than permanent for most cancer survivors. Bradley \& Bednarek [21] found that $67 \%$ of the 141 cancer survivors in their sample employed at the time of diagnosis were still in full-time employment 5-7 years later. Bouknight et al. [22] also found high rates of return to work, with only $18 \%$ of the sample not working 12 months after the diagnosis. Short et al. [23] followed the employment histories of 1433 cancer survivors. The rate of those in employment increased steadily from $43 \%$ between initial diagnosis and 5 months post-diagnosis to $73 \%$ to $6-11$ months post-diagnosis, with $84 \%$ of the sample having returned to work 36-47 months after diagnosis. Sanchez et al. [24] found that $89 \%$ of survivors of colorectal cancer returned to work, with $80 \%$ of them still in employment 5 years later. A study of breast cancer survivors in Ontario found 21\% not in employment 3 years after diagnosis, in comparison to $15 \%$ of a matched cancer-free sample [25]. A study conducted in the Netherlands reported that $64 \%$ of the sample had returned to work 18 months after diagnosis [26]. Amir et al. [27] reported a rate of $82 \%$ among participants resident in the North-West of England. Even though the evidence is that most cancer survivors are eventually able to return to work, it should be noted that a significant minority do not.

\section{Cancer and the Meaning of Work}

The importance of work in patients with cancer has received relatively little attention in the literature. Research that has been conducted suggests that loss of employment negatively affects self-identity, emotional wellbeing, and autonomy [28]. Peteet [14] explained that loss of occupational identity could be a source of significant anxiety and depression. Continuing or returning to the workplace allows many patients to maintain a sense of normalcy or control. The experience of discrimination can become a focus for strong negative feelings about fairness [7]. Social psychologists have documented the importance of work to self-concept, self-esteem, life roles and satisfaction [29]. While these issues have received increasing clinical attention in the rehabilitation of individuals facing disability or retirement [21], they traditionally have been overshadowed by other concerns in the care of patients with lifethreatening illnesses such as cancer. Rehabilitation counsellors need to address work-related distress directly and appreciate the larger significance these themes may have in consumers' coping. A closer look at the importance of work in oncology suggests several areas for future research. Many trials of cancer treatment agents now include quality of life (QOL) instruments that assess patients' ability to function at work, but relatively little attention has been devoted to the emotional impact of changes in work status. The themes of identity, normalcy, and fairness have implications for the care of these patients and suggest several areas for future research $[10,14]$.

Work is important to the self-concept and self esteem of individuals who confront the uncertainties of a diagnosis of cancer. It allows individuals to express and to realize core values, such as creating new knowledge, contributing to society, or providing for one's own support [30]. Identification with a guild or profession is an important component of one's social role. The financial control that comes with a pay check can also help to define one's role at home and influence power dynamics in the family. For some individuals, work is as important to them as their relationships [17]. Despite the fact that as survival rates increase more patients with cancer return to the workplace [31], cancer remains a life-threatening illness that encourages individuals to reassess the basis of their identity and to engage in what may be considered an "existential reprioritization" of core values [32]. Unanticipated changes in employment can 
trigger a disturbing acceleration of this process. For example, involuntary sick leave or retirement may create significant anxiety for a patient whose identity has been closely linked to his or her role as a provider [14].

Cancer may not affect only one's physical wellbeing, routines, and financial status, but also one's relationships with supervisors, mentors, clients, co-workers, and/or institutions [33]. The trauma of losses in these areas often prompts existential questioning and feelings of betrayal, expressed in the familiar questions, "Why me?" and "How could my body let me down like this?" Similar questions about one's worth and place in the larger scheme of things can arise from events at work: "How much does my boss value me and the work that I have done?" "Am I expendable?" "Am I valued only so long as I am useful?" "What does my relationship as a person mean to my boss and/or co-workers?" "Am I being treated fairly?" Concerns about fairness triggered by work can generate powerful feelings of gratitude, resentment or betrayal $[14,34]$.

A benefit of work is that it contributes to a feeling of normalcy. Cancer patients often find that disability not only undermines unique aspects of their identity, but also represents a distressing loss of normalcy, intactness and control [35]. Uncertainty about whether patients will respond to treatment can make realistic vocational planning difficult. Because of fatigue or other physical limitations [36], some patients need to consider a range of work options, including part-time employment or volunteering, both of which can have important positive consequences for individuals coming to terms with disability [37].

\section{Issues Related to Maintaining or Returning to Work}

Cancer refers to a heterogeneous group of diagnoses with a range of prognoses. While the evidence suggests that many survivors will be able to return to work, this is likely to vary significantly by cancer site and treatment. Cancer site is an important variable in this context $[1,2]$. Cancer treatment varies according to the site and stage of the disease and may involve surgery, chemotherapy, radiotherapy and hormone treatment either singly or in combination. Treatment may have a significant impact on an individual's health and associated symptoms that may be physical in nature (including fatigue, nausea, sleep disturbance), psychological (including anxiety and depression) and cognitive. The treatment and associated symptoms are an important factor in determining when individuals feel able to return to work [38]. Among women with breast cancer, Maunsell et al. [25] identified limitations in upper body strength and fatigue as key in determining survivors' ability to return to work. In a prospective study, survivors were two and a half times more likely to stay off work for prolonged periods of time if they experienced high levels of fatigue [26].

In the workplace, discrimination against persons with cancer is a prevalent and continuing concern [7,9]. Arnold [39] reported that workers with cancer were fired or laid off five times as often as other workers. According to Taskila \& Lindbohm [28] a large number of cancer patients have the ability to resume work after treatment. Cancer is, however, a condition that often leads to reduced work ability, and disability in extreme cases. Factors linked to work limitations include type of cancer, form of therapy, education, physical workload, and health status. Spelten et al. [40] systematically reviewed 14 studies conducted between 1985 and 1999 using a work, disease/treatment and person-related framework. They observed that factors facilitating work return were a positive attitude from co-workers and discretion over number of hours and nature of work undertaken. Some work-related factors, particularly physically demanding manual labour, hindered return to work. In terms of disease/treatment factors, only time elapsed since treatment cessation was positively associated with return to work. Interestingly, no conclusive findings were identified across studies in terms of disease stage, cancer site and person-related factors.

The relationships between absenteeism from work, treatment type, and cancer stage were examined by Bradley et al. [17] in a study of survivors with breast and prostate cancers. More prolonged and invasive treatments (chemotherapy, radiotherapy, surgery) were found to be significantly more likely when diagnosis occurs later in the illness trajectory and resulted in lengthier periods of absence from the workplace. Those receiving earlier diagnosis were less likely to undergo such lengthy treatment and reported less absenteeism. While advances in cancer treatment have resulted in improved survival rates, the side effects of treatment continue to be of concern. Reducing side effects of treatment, better screening programs to facilitate earlier diagnosis and clear guidelines for the management of fatigue should improve the ability of survivors to return to work [41]. Social factors are also important in maintaining or returning to work and play a fundamental role in the survivor's ability to resume work after treatment. A survivor who receives more support from friends, family members, and workmates has a greater likelihood of returning to work after therapy [28].

\section{Rehabilitation Counsellors Role with Cancer Survivors}

The effects of cancer and its treatment are likely to impact an individual's ability to work and quality of life, and may present in a combination of adverse effects. Possible concerns include physical factors related to the disease (e.g., disfigurement or pain following surgery) [42], fatigue [26], cognitive functioning [43]; and need for transportation [10]. Many of these effects and consequences of cancer and its treatment may be more enduring and last for many years post treatment. The rehabilitation counsellor needs to be aware of these long-term consequences and, perhaps unlike their role with some other disabilities, be prepared to provide long-term support.

Work adjustment is a support service that may be useful for many cancer survivors. Work adjustment services fall into three broad categories: (1) modified physical load (e.g. reduced weights in manual role or provision of supportive technologies), (2) skill discretion (e.g. re-organization of work), and (3) time discretion (e.g. arranging home working or flexible working). A limited number of studies have examined the role of work adjustments specifically 
for cancer patients. Evidence suggests that, when available, cancer survivors rely heavily on adjustments in time discretion, working reduced hours during and following treatment [41]. Drawing from the wider rehabilitation literature, the benefits of work adjustment can include improving illness management, psychological wellbeing and financial stability or independence [8]. While advances are being made to better understand the consequences of cancer on work, there is also a need to gain a better understanding of the work limitations experienced by cancer survivors during and following treatment, and the work adjustments cancer survivors use to better manage their work.

The workplace itself may be considered for constructive modification or change. To ensure that persons with cancer are protected from discrimination in the workplace, job accommodation is essential. Under the federal legislation (e.g., Rehabilitation Act, ADA of 1990) and under most state anti-discrimination laws, an employer must provide reasonable accommodation to qualified employees with disabilities, unless doing so would mean undue hardship for the employer. A competent multidisciplinary rehabilitation team, a well-educated general public and employers, together with empowered cancer patients can be very effective in eliminating destructive road blocks to employment. Evidence has shown that the cost of closed cancer rehabilitation cases is among the lowest per case for all occupational disabilities including tuberculosis, diabetes, mental disorders, heart disease, and orthopedic problems [44].

Vocational support also requires an awareness of specific knowledge about the condition and its management, the individuals' functional limitations, and demands of the work settings. Because of the variability of the limitations and prognosis with the type and location of cancer, the importance of short-term versus longterm planning should be considered [38]. Some interventions, such as meetings with a nurse at the treating hospital department to start early vocational rehabilitation, meeting with the participant, occupational physician, and supervisor to make a return-towork plan, and providing letters from a treating physician to an occupational physician to enhance communication are currently being studied. The aim of these work-directed interventions is to improve cancer patients' care and to enhance their return-to-work and quality of life [9]. Pryce et al. [20] indicated that opportunities to work flexibly, disclosure to colleagues, difficulties managing fatigue, and paid time off to attend all medical appointments are crucial considerations that should be associated with continuing to work during treatment. Correlates of return to work included difficulties managing fatigue, managing the stress of cancer, managing physical changes associated with cancer, received advice from doctor about and return to work meeting with employer [9].

\section{Psychological Issues in Cancer}

Regardless of the type of cancer or the type of intervention instituted, psychological issues arise in all individuals with cancer [38]. Psychological distress has been found to be a major and continual problem in patients diagnosed with cancer. The long-term psychological and emotional side effects of cancer and its therapy include loss of memory, anxiety, depression, concentration deficits, reduced social skills and sexual problems [34,45-47]. A certain degree of psychological stress is common, especially associated with initial diagnosis, and approximately fifty percent of patients go through severely high levels of depression and anxiety, which greatly affects their life quality [48].

Depression and anxiety associated with a cancer diagnosis not only affects the patients' quality of life, but also their mortality rate. Several research studies indicated that the mortality rate was high in cancer patients who reported high depression levels. Results indicated that there was 2.6 times more likelihood of dying within the first nineteen months in patients diagnosed with previous psychological issues $[1,30,47]$. Despiteadvances in management, the word "cancer" still generates fear and anxiety in many individuals and is stigmatizing for others. Regardless of the actual prognosis, individuals may fear loss of relationships, independence, job, and integrity of the body. Cancer may be also a symbol of vulnerability, loss of control, or helplessness [38]. Overlooking psychological problems caused by cancer diagnosis not only exacerbates illness, but it also results to increased health care costs.

Among the key implications of the review presented in this article is for future researchers to focus more on the emotional and psychological issues that patients diagnosed with cancer as well as their families experience. Specifically, research is needed to determine precisely which psychosocial factors may influence fulfilment of the patients and relatives needs [49]. Schmid-Buchi et al. [50], for example, found that family members' needs primarily concerned access to information and communication with health care professionals. Addressing these issues will not only improve cancer patients' quality of life, but it will also minimize the rates of mortality [48].

Unemployment among cancer's survivors may also impact the psychological health for these individuals. Unemployment or losing job is profoundly distressing, particularly when unexpected or involuntary, may take its toll on mental health [21]. A body of scientific evidence provides evidence that unemployed people manifest lower levels of psychological wellbeing than do their employed peers $[9,10,13,51]$. Unemployment has been linked with a number of psychological disorders, particularly anxiety, depression, and substance abuse. In addition, behaviors including suicide and violence toward family members or others also correlate with unemployment.

\section{Cancer and Social Life}

A cancer diagnosis is a crisis in an individual's life. It results to changes in role, identity and social interactions. An uncertain future is presented. An individual with cancer often experiences a change in relationships with people in their lives; changes that involve relationships with friends, family members, workmates, and other people are typical [44]. Edwards \& Clarke [29] noted that 
a cancer diagnosis is a stressful event for both patients and their loved ones. It is not uncommon to find patients and family members experiencing serious stress reactions and anxiety levels. There is a need for cancer patients to develop effective coping strategies so that they can manage these stressed relationships with their friends, families and other people around them [30,34,46,52,53]. Receiving optimal care and support is a significant step towards coping with cancer.

Social support is one of the most effective mechanisms that patients diagnosed with cancer can employ. Social support has also been shown to reduce the levels of anxiety and stress as well as the rates of mortality [54]. Social support can be obtained from family members, friends and partners [55]. Structured, multidisciplinary counselling groups provide an effective platform for social support and encouragement [56,57]. Social support groups enable participants to receive support from peers in a forum that fosters the sharing of ideas, information, concerns, and problem-solving method. Several studies of patients with cancer reported that patients who participate in structured group counselling programs have been found to report lower levels of anxiety and depression and higher levels of quality of life compared to those who did not take part in such programs. The results suggested that group counselling sessions provide an effective platform for patients to gain strength and support from peers, and share their experiences $[57,58]$.

Some research studies indicate that the rates of survival of cancer patients have increased with appropriate therapy. Donald [55] found that group counselling boosts immunity and improved health habits for individuals diagnosed with cancer. In this study, patients in the intervention group met weekly in small-group sessions to learn ways to lower their stress, improve their mood, modify key health behaviours and follow their treatment plans. These interventions helped patients in the treatment group in lowering the psychological stress and improving mood as well as getting more support from friends and family. In addition, a significant number of patients in the intervention group developed healthier eating habits and quit smoking. In assessing the strength of the patients' immune systems, scientists measured the numbers of T-cells and certain T-cell subsets in both groups. They also evaluated the ability of the T-cells to grow and multiply. After controlling of all other variables, researchers found no significant change in the numbers of T-cell or NK cells present. They discovered, however, that women in the intervention group showed a stable or improved T-cell proliferative capacity.

Challenges that confront family members of individuals with cancer are shaped by the type of cancer, the extent of the cancer, the type of intervention implemented, and the quality of the family relationship prior to diagnosis [59]. Family functioning plays a fundamental role in influencing the levels of stress and anxiety in patients with cancer and their relatives. Lower depression levels were reported in families that could openly express their feelings, act freely, and find effective solutions to different problems.
Additionally, lower anxiety levels were reported in families that had a form of communication that was direct rather than restricted [29].

Unemployment among cancer's survivors has a negative impact on their quality of life as well. Some studies indicate that unemployment itself causes anxiety, helplessness, depression, and stress and has been shown to be associated with sleeping problems and strained relationships, and avoiding social situations [60]. According to Jackson [60], employment compels contacts and shared experiences with others outside the nuclear family and provides goals and purposes, which are beyond the scope of an individual. The stress associated with unemployment may also affect close family members as well. McLoyd \& Flanaqan [61] concluded, after an extensive literature review, that children with unemployed fathers are at risk of socio-emotional problems, deviant behaviour, and reduced aspirations and expectations. The child may also model the somatic complaints of the father. Tu [62] cited specific evidence regarding the consequences of financial stress, which are: mental health problems, withdrawal from peers, depression, loneliness, emotional sensitivity, distrustfulness, decreased sociability and low self-esteem. Research conducted by Murphy and Athanasou \& Murphy GC [63] pointed to the difficulties spouses, generally female partners of unemployed men, face in trying to manage on reduced income, to cope with the spouses' intrusive presence in the household, to support distressed partners and deal with intra-family conflict.

\section{Role of the Rehabilitation Counsellor}

The rehabilitation counsellor's responsibilities include assisting individuals with cancer in psychosocial adjustment and coping, and addressing environmental discrimination and barriers, psychological conflict or distress, and loss of functional ability. Establishing the degree of efficacy of psychosocial interventions on the quality of life of individuals diagnosed with cancer is crucial. The primary types of effective interventions include social support, patient education, psychotherapeutic interventions, and training on coping skills [24]. Rehse \& Pukrop [48] concluded that there was an improved quality of life in patients with cancer who received social support, education, training on coping skills, and psychotherapeutic interventions. They estimated that psychosocial interventions that lasted for a minimum period of twelve weeks resulted in improved quality of life in cancer patients. The findings of this review indicate that psychosocial interventions should be a part of cancer patients' therapeutic programs. Some patients can be helped to put their core values and accomplishments into perspective by a life review conducted as part of an initial evaluation [64]. Others may need "permission" to grieve the loss of work and work-related relationships at a time when family and others may be more focused on other matters. Yet, others may need sensitive exploration of and help working through deeper concerns for which a focus on work has become a surrogate, such as a loss of autonomy, control, or trust in others [65]. 
Experienced counsellors or clinicians may also be able to counsel patients about when to consider returning to part-time work, volunteering, retiring early, or consulting an attorney about suspected job discrimination. Cancer patients report that they receive limited advice from treating physicians, general practitioner, and occupational therapist about return-to-work issues $[8,20]$. Thus, rehabilitation counsellors can assist cancer patients and employers with workplace accommodations (e.g., modified work schedule, job sharing, break and rest periods), especially since the most frequently reported hindering factor for cancer patients is fatigue [9]. Often, upon return to work, cancer patients must contend with numerous questions and discomfort from co-workers. Counsellors may be able to facilitate communication and understanding among various parties. It is not uncommon for cancer patients not being able to return to their former type of employment. As such, the rehabilitation counsellor is able to work with cancer patients on job seeking skills and identifying transferable skills. Equally as important is helping the individual to decide if he or she is interested in obtaining and maintaining competitive employment, part-time work, or volunteer work.

One of the primary roles of rehabilitation counsellors is to gain better understanding for the environmental and personal factors and how their interactions influence the work-related outcomes of survivors with cancer [66]. The rehabilitation counsellor may learn from the expertise of other medical specialists and occupational therapists working to improve the vocational rehabilitation of patients in other settings [21]. Rehabilitation counsellors along with other professionals must be able to identify the demand occupations in the new economy (i.e., the largest or fastest growth areas of employment opportunities) and develop effective approaches to help people with disabilities develop the required skill sets to meet employer expectations and work environments. Rehabilitation counsellors in conjunction with other professionals must have a thorough understanding of the real concerns and attitudes of employers about hiring and retaining people with disabilities and be able to address their concerns [67]. Previous studies have reported that supportive work environment and good social climate at the workplace are stronger factors for enhancing the return-to-work of cancer survivors [22,68-71].

Vocational rehabilitation is only one aspect that cancer patients and survivors need to address. When considering the holistic approach, the rehabilitation counsellor may want to work with cancer patients in the areas of developing independent living skills, recreation and leisure, and identification of community resources. Empowerment, self-advocacy, and choice/decision making are other areas in which a rehabilitation counsellor can offer the cancer patient counselling and guidance.

\section{Conclusion}

Cancer patients have a higher risk of unemployment and are more vulnerable to psychosocial distress than those without cancer. Work is important for both patients with cancer themselves and society at large. Patients often regard returning to work as a symbol of recovery and regaining a normal life. For society, it is an economic and social benefit to encourage patients to return-to-work whenever possible. Psychosocial issues are also important aspects the rehabilitation counsellor should take in account to facilitate the independence, life-satisfaction, and integration in society. Social support, patient education, psychotherapeutic interventions, and training on coping skills are techniques that are likely to have a positive impact on the rehabilitation process.

We dare not forget the simple truth put forth by Harold Dodds (American educator and 15th President of Princeton University) that "No, work is not an ethical duty imposed on us from without by a misguided and outmoded Puritan morality; it is a manifestation of individual's deepest desire that the days of each one's life shall have significance" [44]. Patients living with cancer desire significance in their daily activities to the same degree as those who are healthy [44]. Holistically, impairment in one aspect of life may affect all other aspects. Psychological, social, and occupational domains interact and influence each other, so touching and discussing all these aspect with our consumers with cancer will guarantee enhancing the full view of these survivors' life.

\section{References}

1. American Cancer Society (2014) Cancer facts \& figures, 2014. Atlanta, Georgia.

2. Centers for Disease Control and Prevention (2004) A national action plan for cancer survivorship: Advancing public health strategies.

3. Drake K (2012) Quality of life foer cancer patients: From diagnosis to treatment and beyond. Nurs Manage 43(2): 20-25.

4. Karki A, Simonen R, Malkia E, Selfe J (2005) Impairments, activity limitations and participation restrictions 6 and 12 months after breast cancer operation. J Rehabil Med 37(3): 180-188.

5. Caravati-Jouvenceaux A, Launoy G, Klein D, Henry-Amar M, Abeilard E, et al. (2011) Health-related quality of life among long-term survivors of colorectal cancer: A population-based study. Oncologist 16 (11): 16261636.

6. Carlson L, Angen M, Cullum J, Goodey E, Koopmans J, et al. (2004) High levels of untreated distress and fatigue in cancer patients. $\mathrm{Br} \mathrm{J}$ Cancer 90(2): 2297-2304.

7. Hoffman B (2008) Working it out: Your employment rights as a cancer survivor. National Coalition for Cancer Survivorship, Washington, USA.

8. Kennedy F, Haslam C, Munir F, Pryce J (2007) Returning to work following cancer: A qualitative exploratory study into the experience of returning to work following cancer. BMC Cancer 16(1): 17-25.

9. Tamminga S, de Boer A, Verbeek J, Taskila T, Frigns-Dresen M (2010) Enhancing return to work in cancer patients, development of an intervention and design of a randomised controlled trial. BMC Cancer 10(354): 2-9.

10. Adler NE, Page AKE (2008) Cancer care for the whole patient: Meeting psychosocial health needs.

11. Mehnert A (2011) Employment and work-related issues in cancer survivors. Crit Rev Oncol Hematol 77(2): 109-130.

12. Illingworth N, Stoddart K, Hubbard G (2009) Employment and cancer: A narrative review of the evidence. Cancer Care Research 12(89): 2-8. 
13. Kyle RG, Culbard B, Evans J, Gray NM, Ayansina D, et al. (2011) Vocational rehabilitation service for patients with cancer: Design of a feasibility study incorporating a pilot randomized controlled trail among women with breast cancer following surgery. Trials 12(89): 1-8.

14. Peteet J (2000) Cancer and the meaning of work. Gen Hosp Psychiatry 22(3): 200-205.

15. Bennett J, Brown P, Cameron L, Whitehead L, Porter D, et al. (2008) Changes in employment and household income during the 24 months following a cancer diagnosis. Support Care Cancer 7(8): 1057-1064

16. De Boer A, Taskila T, Ojajärvi A, Van-Dijk F, Verbeek J (2009) Cancer survivors and unemployment-A meta-analysis and meta-regression. JAM, 301(7): 753-762.

17. Bradley C, Oberst K, Schenk M (2006) Absenteeism from work: The experience of employed breast and prostate cancer patients in the months following diagnosis. Psychooncology 15(10): 739-747.

18. Arnetz B, Sjogren B, Rydehn B (2003) Early workplace intervention for employees with musculoskeletal-related absenteeism: A prospective controlled intervention study. J Occup Environ Med 45(5): 499-506.

19. De-Boer A, Zanten-Przybysz I, Maes L, Frings-Dresen M (2008) Return to work after treatment for cancer: Experiences of patients and supervisors in Dutch: TBV 16(10): 292-297.

20. Pryce J, Munir F, Haslam C (2007) Cancer survivorship and work: symptoms, supervisor response, co-worker disclosure and work adjustment. J Occup Rehabil 17(1): 83-92.

21. Bradley C, Bednarek H (2002) Employment patterns of long-term cancer survivors. Psychooncology 11(1): 188-198.

22. Bouknight R, Bradley C, Luo Z (2006) Correlates of return to work for breast cancer survivors. J Clin Oncol 24(2): 345-353.

23. Short P, Vasey J, Tunceli K (2005) Employment pathways in a large cohort of adult cancer survivors. Cancer 103(6): 1292-1301.

24. Sanchez K, Richardson J, Mason H (2004) The return to work experiences of colorectal cancer survivors. AAOHN J 52(12): 500-510.

25. Maunsell E, Drolet M, Brisson J, Brisson C, Masse B, et al. (2004) Work situation after breast cancer: results from a population-based study. J Natl Cancer Inst 96(24): 1813-1822.

26. Spelten E, Verbeek J, Uitterhoeve A, Ansink A, Van-Der J, et al. (2003) Cancer, fatigue and the return of patients to work: A prospective cohort study. Eur J Cancer 39(11): 1562-1570.

27. Amir Z, Moran T, Walsh L, Iddenden R, Luker K (2007) Return to paid work after cancer: a British experience. J Cancer Surviv 1(2): 129-136.

28. Taskila T, Lindbohm M (2007) Factors affecting cancers survivors' employment and work ability. Acta Oncologica 46(4): 446-510.

29. Edwards B, Clarke V (2004) The psychological impact of cance diagnosis families: the influence of family functioning and patients' illness characteristics on depression and anxiety. Psychooncology 13(8): 562-576.

30. Dunkel-Schetter C, Feinstein L, Taylor S, Falke R (1992) Patterns of coping with cancer. Health Psychol 11(2): 79-87.

31. Taskila T, Pukkala E, Martikainen R, Karjalainen A, Hietanen P (2005) Employment status of finish cancer patients in 1997. Psychooncology 14(10): 221-226

32. Taskila T, Martikainen R, Virtanen S, Pukkala E, Hietanen P, et al. (2004) The impact of education and occupation on the employment status of cancer survivors. Eur J Cancer 40(16): 2488-2493.

33. Feuerstein M, Hansen J, Calvio L, Johnson L, Ronquillo J (2007) Work productivity in brain tumor survivors. J Occup Environ Med 49 (11): 803-811.
34. Herschbach P, Keller M, Knight L, Brandl T, Huber B, et al. (2004) Psychological problems of cancer patients: A cancer distress screening with a cancer-specific questionnaire. Br J Cancer 91(3): 504-511.

35. Hoffman B (2005) Cancer survivors at work: A generation of progress. CA Cancer J Clin 55(9): 271-280.

36. Verbeek J, Spelten E, Kammeijer M, Sprangers M (2003) Return to work of cancer survivors: A prospective cohort study into the quality of rehabilitation by occupational physicians. Occupational Environmental Medicine 60(10): 352-357.

37. Nieuwenhuisjen K, Bos-Ransdorp B, Uitterhoeve L, Sprangers M Verbeek J (2006) Enhanced provider communication and patient education regarding return to work in cancer survivors following curative treatment: a pilot study. J Occup Rehabil 16(3): 647-657.

38. Falvo D (2009) Medical and psychosocial aspects of chronic illness and disability. Jones \& Bartlett Publishers, Canada.

39. Arnold K (1999) American with disabilities act: Do cancer patients qualify as disabled? Journal of National Cancer Institute 91(10): 822826

40. Spelten E, Sprangers M, Verbeek J (2002) Factors reported to influence the return to work of cancer survivors: a literature review. Psychooncology 11(2): 124-131.

41. Bradley C, Neumark D, Bednarek H, Schenk M (2005) Short-term effects of breast cancer on labor market attachment: Results from a longitudinal study. J Health Econ 24(10): 137-160.

42. Chirikos T, Russell-Jacobs A, Hacobsen P (2002) Functional impairment and the economic consequences of female breast cancer. Women Health 36(1): $1-20$

43. Minisini A, Atalay G, Bottomley A, Puglusu F, Piccart M, et al. (2004) What is the effect of systemic anticancer treatment on cognitive function? Lancet Oncology 5(5): 273-282.

44. Brown H, Ming TS (2005) Vocational rehabilitation of cancer patients. Semin Oncol Nurs 8(3): 201-211.

45. Bloch S, Love A, Macvean M, Duchesne G, Couper J, et al. (2007) Psychological adjustment of men with prostate cancer: A review of the literature. Biopsychosoc Med 1(2): 1-3.

46. O'Sullivan CK, Bowqles KH, Jeon S, Ercolano E, McCorkle R (2011) Psychological distress during ovarian cancer treatment: Improving quality by examining patient problems and advanced practice nursing interventions. Nurs Res Pract 2011: 351642.

47. Watson M (2001) Psychosocial issues in cancer. Current Science 81(5): 566-570.

48. Rehse B, Pukrop R (2003) Effects of psychosocial interventions on quality of life in adult cancer patients: meta analysis of 37 published controlled outcome studies. Patient Education and Counseling 50(2): 179-186.

49. Schmid-Buchi S (2008) A review of psychosocial needs of breast cancer patients and their relatives. J Clin Nurs 17(21): 2895-2909.

50. Schnid-Buchi S (2008) Psychosocial problems and needs of posttreatment patients with breast cancer and their relatives. Eur J Oncol Nurs 15(3): 260-266.

51. Turner B (1995) Economic context and the health effects of unemployment. J Health Soc Behav 36(3): 213-229.

52. Hodges LJ, Humphris GM, Macfarlane G (2005) A meta-analytic investigation of the relationship between the psychological distress of cancer patients and their carers. Soc Sci Med 60(1): 1-12.

53. Kurtz ME, Kurtz JC, Given CW, Given BA (2004) Depression and physical health among family caregivers of geriatric patients with cancerlongitudinal view. Med Sci Monit 10(8): 447-456. 
54. Bishop M, Harley DA (2009) Groups in rehabilitation settings. In: Capuzzi D, Gross DR, Stauffer MD (Eds.), Introduction to Group Work (5 ${ }^{\text {th }}$ edn), Love Publishing Company, Denver, USA.

55. Donald A (2004) Counselling boosts immunity and improves health habits. Journal of Clincal Oncology 12(59): 37-46.

56. Cunningham AJ, Edmonds CV (1996) Group psychological therapy for cancer patients: A point of view, and discussion of the hierarchy of options. Int J Psychiatry Med 26(1): 51-82.

57. Ferlic M, Goldman A, Kennedy B (1979) Group counselling adult patients with advanced cancer. Cancer 43(2): 760-786.

58. Helgeson V, Cohen S (1996) Social support and adjustment to cancer: Reconciling descriptive, correlational, and intervention research. Health Psychol 15(2): 135-148.

59. Sherman A, Simonton S (2001) Coping with cancer in the family. The Family Journal 9(2): 193-200.

60. Jacobsen P (2007) Systematic review and metal-analysis of psychological and activity-based interventions for cancer-related fatigue. Health Psychol 26(6): 202-378.

61. Mcloyd V, Flanaqan C (1990) Economic Stress: Effects on family life and child development. Jossey-Bass, Michigen, USA.

62. Tu HT (2004) Rising health costs, medical debt and chronic conditions. Center for Studying Health System Change, Washington, USA.
63. Murphy GC, Athanasou TA (1999) The effect of unemployment on mental health. J Occupa Org Psychol 72(1): 83-99.

64. Choi KS, Kim EJ, Lim JH, Kim SG, Lim MK, et al. (2007) Job loss and reemployment after a cancer diagnosis in Koreans: a prospective cohort study. Psychooncology 2(16): 205-213.

65. Amir Z, Neary D, Luker K (2008) Cancer survivors' views of work 3 years post diagnosis: a UK perspective. Eur J Oncol Nurs 12(2): 190-197.

66. Wong WK (2012) Employment quality in adult survivors of childhood cancer (Doctoral dissertation).

67. Amir Z, Wynn P, Chan F, Strauser DR, Whitaker S, et al. (2010) Return to work after cancer in the UK: Attitudes and experiences of line managers. J Occup Rehabil 20(4): 435-442.

68. Amir Z, Brocky J (2012) Cancer survivorship and employment. Occup Med 59(6): 373-377.

69. Feuerstein M, Luff G, Harrington C, Olsen C (2007) Patterns of workplace disputes in cancer survivors: A population study of ADA claims. J Cancer Surviv 28(1): 185-192.

70. Jackson T (1999) Differences in psychosocial experiences of employed, unemployed, and student samples of young adults. The Journal of Psychology 133(1): 49-60.

71. Robyn R, Mundy S, Moore G (1992) A missing kink: Rehabilitation counseling for person with cancer. The Journal of Rehabilitation 58(1): $47-50$

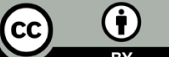

Creative Commons Attribution 4.0 International License

For possible submissions Click Here
Submit Article

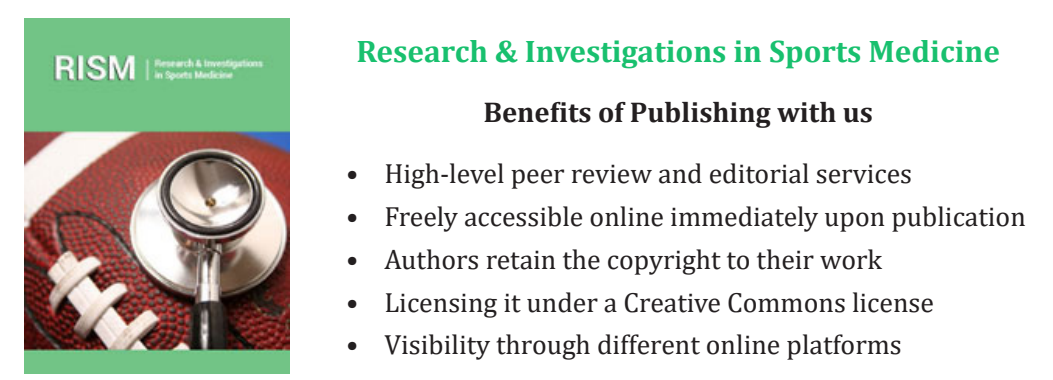

